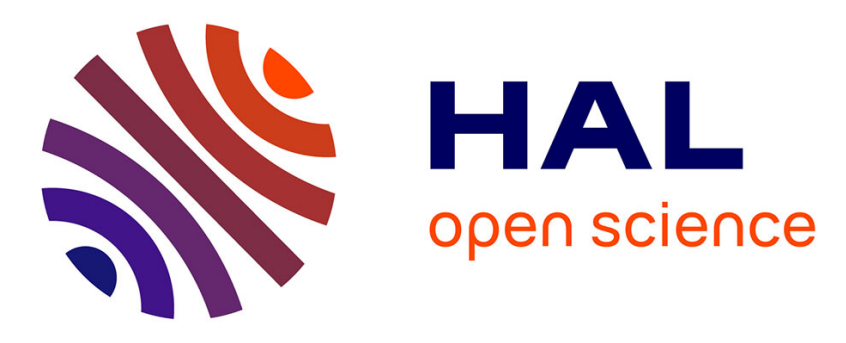

\title{
Motion of the lips of brass players during extremely loud playing
}

Samuel Stevenson, Murray Campbell, Seona Bromage, John Chick, Joël Gilbert

\section{- To cite this version:}

Samuel Stevenson, Murray Campbell, Seona Bromage, John Chick, Joël Gilbert. Motion of the lips of brass players during extremely loud playing. Journal of the Acoustical Society of America, 2009, 125 (4), pp.EL152-EL157. hal-00474634

\section{HAL Id: hal-00474634 https://hal.science/hal-00474634}

Submitted on 22 Apr 2010

HAL is a multi-disciplinary open access archive for the deposit and dissemination of scientific research documents, whether they are published or not. The documents may come from teaching and research institutions in France or abroad, or from public or private research centers.
L'archive ouverte pluridisciplinaire HAL, est destinée au dépôt et à la diffusion de documents scientifiques de niveau recherche, publiés ou non, émanant des établissements d'enseignement et de recherche français ou étrangers, des laboratoires publics ou privés. 


\title{
Motion of the lips of brass players during extremely loud playing
}

\author{
Samuel Stevenson, ${ }^{\text {a) }}$ Murray Campbell, and Seona Bromage \\ School of Physics, \\ University of Edinburgh, \\ $U K$ \\ John Chick \\ School of Engineering and Electronics, \\ University of Edinburgh, \\ UK \\ Jöel Gilbert \\ Laboratoire d'Acoustique de L'Université du Maine (UMR CNRS 6613), \\ Avenue Olivier Messiaen, \\ 72085 Le Mans Cedex 9, \\ France
}

Samuel Stevenson: Motion of the brass players lips during extremely loud playing 1 


\begin{abstract}
When a brass instrument is played loudly the energy level of the higher harmonics increases dramatically. The generally accepted explanation for this is non-linear steepening of the wavefront and generation of shock waves within the instrument bore. However, it has also been suggested that changes in the player's lip vibration could play a role in generating this 'brassy' sound. To test this hypothesis, the dependence of lip opening-area on time has been measured for different dynamic levels in trombones and horns. Results suggest that the behaviour of the open area does not change dramatically when the instrument enters the brassy regime.
\end{abstract}

PACS numbers: $43.75 \mathrm{Fg}$ 


\section{Introduction}

One striking feature of orchestral brass instruments is that the timbre is strongly dependent on dynamic level. At the loudest levels, the sound becomes distinctly 'brassy' or 'cuivré'. This dramatic effect occurs due to a marked increase in the energy levels of the higher harmonics ${ }^{1,2}$, and brass musicians commonly use this timbral change as a form of musical expression. It is interesting to note that the effect is more dominant in some instruments than others; for instance, the trombone is generally considered to be 'brassier' than the euphonium.

Musical tones are generated in brass instruments as a result of the self-sustained oscillation of the lips of the player ${ }^{3}$. Air flows from the lungs of the player into the mouthpiece of the instrument via the lips, which act as a valve modulating the airflow. This paper describes an experimental study of brass instrument playing at high dynamic levels, and examines the the relationship between changes in the nature of the lip motion and the development of 'brassy' timbre.

It is now generally acknowledged that the onset of the brassy regime is primarily a result of the non-linear propagation of the acoustic wavefront along the bore of the instrument, as clearly demonstrated by Hirschberg et $a l^{2}$. When high amplitude pressure oscillations are generated by the lips, the leading edge of the pressure wave steepens as it progresses through the bore of the instrument. If the air column of the instrument is sufficiently longand the amplitude of the oscilations high enough - then the pressure rise becomes nearly instantaneous. This 'shock-wave' formation gives rise to an increase in the higher frequency components in the tone which is produced. ${ }^{4}$

It has also been suggested by some researchers that the degree to which the lips can open becomes 'saturated' or 'clipped' during extremely loud playing as the movement of the lips becomes constrained by the rim and cup walls of the mouthpiece ${ }^{5-7}$. This effect, if present,

a)Electronic address: samuel.stevenson@ed.ac.uk 
Stevenson, JASA-EL

would contribute significantly to the production of a 'brassy' sound. Martin ${ }^{8}$ performed some early measurements in which he showed that during mezzo forte playing on the cornet the variation of lip open area with time was almost sinusoidal. Another study, using trombones, showed that the open area between the lips did not behave purely sinusoidally ${ }^{9}$. In fact, the 'closing' phase of the lip motion took longer than the 'opening' phase. This effect was more pronounced in large amplitude playing.

\section{Experimental method}

Three musicians — skilled amateurs with many years playing experience - were asked to sound pairs of notes at the same pitch but differing dynamic levels: one clearly 'brassy' to the ear of the player and the other 'non-brassy'. The sound radiated from the bell of the instrument was captured using a Brüel and Kjær 4192 microphone at a distance of one bell radius. A PCB 106B pressure transducer, with probe attachment, was inserted into the mouthpiece to capture the pressure waveform at the input of the instrument. The setup for the horn can be seen in figure 1 (left).

In order to allow optical access to the lips, transparent mouthpieces, as developed by Bromage $^{10}$, were used (figure 1 (right)). The key acoustic properties of the mouthpieces (throat, shank, cup volume and rim dimensions) were based on current production designs in order to ensure that the mouthpieces are both realistic and comfortable for the player.

The motion of the lips was captured by a Phantom v.4 high speed digital camera recording at 6000 frames per second. At this speed, a strong light source is required and so a Schott KL1500 model cold light source was used to illuminate the lips. The captured footage was then split into a series of numbered greyscale bitmaps, one for each frame.

A threshold grey level was set. All pixels with a greyscale value above the threshold were set to white and all below the threshold (corresponding to the open area of the lips) set to black. This 'binary' process can be seen in figure 2. For each image the number of black pixels was counted and the lip open area as a function of time was deduced. 


\section{Results}

Figure 3 shows examples of the radiated and mouthpiece pressure waveforms, recorded on a tenor trombone playing the notes $\mathrm{F}_{3}$ and $\mathrm{B}_{3}$, for both brassy and non-brassy playing. Inspection of the mouthpiece pressure signals (figure 3 (left)) shows that the amplitude of the signal increases as expected from non-brassy to brassy playing, but the waveforms are broadly similar. In contrast, comparison of the radiated sound pressures (figure 3 (right)) shows that there is a dramatic change in the form of the pressure signal between non-brassy and brassy playing. Non-linear propagation implies distortion of the pressure wave, which in turn can lead to the formation of a shock-wave. Here, there is clear evidence of shock-wave formation within the bore of the instrument, in agreement with the results of Hirschberg et. $a l^{2}$.

Analysis of the pressure signals recorded on the horn show similar behaviour to that of the trombone, as can be seen from the online multimedia files mm01 and mm02. These are stereo recordings of the pressure signal in the mouthpiece (left channel) and the radiated sound (right channel) during brassy (mm01) and non-brassy (mm02) playing.

mm01. A stereo recording of the pressure signal in the mouthpiece (left channel) and radiated sound (right channel) of a horn during brassy playing. Note C4. The starting transient has been removed. This is a file of type 'wav'. Size (258kB)

mm02. A stereo recording of the pressure signal in the mouthpiece (left channel) and radiated sound (right channel) of a horn during non-brassy playing. Note C4. The starting transient has been removed. This is a file of type 'wav'. Size (258kB)

The spectral centroid represents the distribution of power over frequency and provides a quantitative measurement of the increase in energy of the higher harmonics. It is defined as 


$$
F_{S C}=\frac{\sum_{i=1}^{n} F_{i} A_{i}}{\sum_{i=1}^{n} A_{i}},
$$

where $F_{i}$ is the frequency of the $i^{\text {th }}$ harmonic and $A_{i}$ represents the amplitude of that harmonic.

The spectral centroids for both the mouthpiece pressure and the radiated sound during both brassy and non-brassy playing are shown in Table I for two notes recorded on the tenor trombone and for two recorded on the horn. For the note $\mathrm{B}_{3}$ on the trombone, in the case of non-brassy playing, the spectral centroid increases from $304 \mathrm{~Hz}$ in the mouthpiece to $716 \mathrm{~Hz}$ in the radiated sound - an increase by factor 2.3. In the case of brassy playing, the centroid increases from $369 \mathrm{~Hz}$ to $1816 \mathrm{~Hz}$, an increase by factor 4.9 . The spectral centroid of the sound recorded in the mouthpiece increased by a factor 1.2 in the transition from non-brassy to brassy playing. In contrast, the ratio between the radiated spectral centroids is much larger - a factor of 2.5. It is clear from the data shown in the table that the note $\mathrm{F}_{3}$ as played on the trombone and the notes $\mathrm{C}_{4}$ and $\mathrm{F}_{3}$ on the horn show a similar trend. This suggests that the main source of the brassy sound does not come from within the mouthpiece of the instrument, but instead comes further downstream before the sound is radiated to the air. This quantitative analysis of the spectral centroid agrees with our qualitative visual analysis of the pressure waveforms shown in figure 3 .

Figure 4 shows the lip open areas for both brassy and non-brassy playing for two notes on two different instruments - tenor trombone $\left(\mathrm{Bb}_{3}\right.$ and $\left.\mathrm{F}_{3}\right)$ (left) and horn $\left(\mathrm{C}_{4}\right.$ and $\left.\mathrm{F}_{3}\right)$ (right). The brassy/non-brassy 'pairs' are displayed with a common time axis, but each lip open area curve has its amplitude data displayed on a separate y-axis (brassy on the left, non-brassy on the right). Videos of both brassy and non-brassy playing corresponding to the note $\mathrm{C} 4$ on the horn are supplied as online multimedia in mm03 and mm04 respectively.

mm03. A sample video of the lips of a horn player during brassy playing. Note C4. Framerate of five frames per second. This is a video of type 'avi'. Size (363kB) 
Stevenson, JASA-EL

mm04. A sample video of the lips of a horn player during non-brassy playing. Note C4. Framerate of five frames per second. This is a video of type 'avi'. Size (363kB)

A previous study, by Bromage ${ }^{10}$, found that the width of the lip opening increased quickly in the early part of the vibration cycle, and then remained at a constant value for much of the rest of the cycle. For louder notes, the width was constant for a greater proportion of the cycle than for quieter playing. However, it is the lip open area which is the primary variable by which the airflow into the instrument is controlled. From figure 4 it is immediately clear that the brassy/non-brassy pairs behave very similarly with respect to the lip open area. The only obvious difference between brassy and non-brassy playing is that, as expected, the brassy lip open areas have a larger amplitude than their non-brassy counterparts. For each brassy/non-brassy pair of measurements, the waveforms of the lip open area as a function of time are very similar, and do not show evidence of clipping in the brassy regime.

\section{Conclusions}

Spectral centroid data for the pressure signals in the mouthpiece and outside the bell of trumpets, horns and trombones support the hypothesis that the primary source of the increase in energy of the higher harmonics in very loud playing is to be found within the bore of the instrument. Studies of the lip motion of brass instrument players using transparent mouthpieces and a high speed digital camera show that the behaviour of the lip open area does not vary significantly between brassy and non-brassy playing, providing confirmation that variations of the lip open area with amplitude are not the main source of the distinctive timbre of brass instruments at high dynamic levels.

\section{Acknowledgments}

This work was funded by a Ph.D. grant from the EPSRC, UK. The authors wish to thank all the musicians who offered their time and musical expertise. 


\section{References and links}

1 J. Backus and T.C. Hundley, 'Harmonic generation in the trumpet', J. Acoust. Soc. Am., Vol. 49, pp. 509-519 (1971)

2 A. Hirschberg, J. Gilbert, R. Msallam and A.P.J. Wijnands , 'Shock Waves in Trombones', J. Acoust. Soc. Am., Vol. 99 (3), pp. 1754-1758 (1996)

3 S. Elliot and J.M. Bowsher, 'Regeneration in brass wind instruments', J. Sound Vib., Vol. 83, pp. 181-217 (1982)

4 J. Gilbert, L. Menguy, D.M. Campbell, 'A simulation tool for brassiness studies', J. Acoust. Soc. Am., Vol 123, pp. 1854-1857 (2008).

5 G. Widholm, 'The Vienna Horn - a historic relic successfully used by top orchestras of the 21st Century', in Proceedings of Forum Acusticum Budapest 2005, Budapest, Hungary; 29 Aug-2 Sep 2005, pp. 441-445.

6 T.R. Moore, E.T. Shires, I.E.W. Codery and A. Daniels, 'The Effect of Bell Vibrations on the Sound of the Modern Trumpet', Acta Acustica united with Acustica, Vol. 91, pp. $578-589(2005)$

7 N.H. Fletcher and A.Tarnopolsky, 'Blowing pressure, power and spectrum in trumpet playing', J. Acoust. Soc. Am., Vol. 105 (2), pp. 874-881 (1999)

8 D.W. Martin, 'Lip vibrations in a cornet mouthpiece', J. Acoust. Soc. Am. Vol. 13, pp. 305-309 (1942)

9 J. Chick, S. Bromage, D. M. Campbell, S. Stevenson, J. Gilbert, 'Motion of the brass player's lips during extreme loud playing', Proceedings of the Bème Congrès Français d'Acoustique, Tours, 2006

10 S. Bromage, 'Visualisation of the lip motion of brass instrument players, and investigations of an artificial mouth as a tool for comparitive studies of instruments', Ph.D. thesis, The University of Edinburgh. (2006) 
Stevenson, JASA-EL

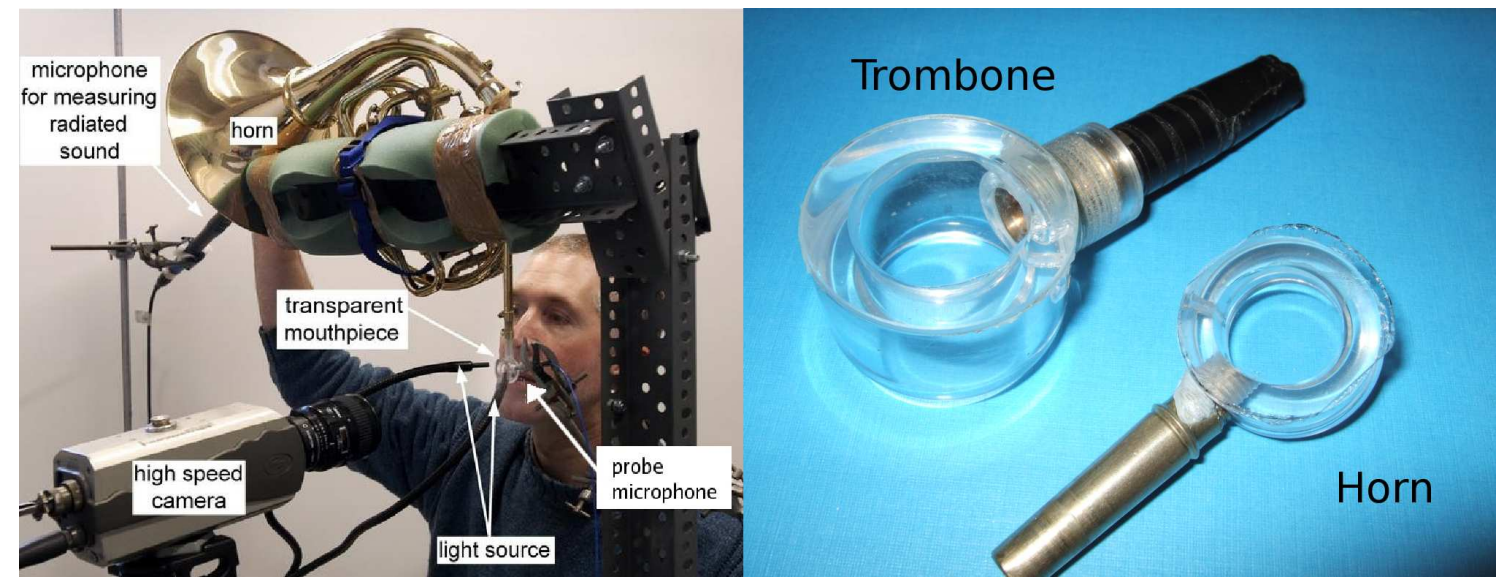

FIG. 1. An overview of the complete experimental setup (left) for the horn showing the placement of the microphones, camera, and lightsource. The transparent mouthpieces (right) for both trombone and horn. (Colour online) 
Stevenson, JASA-EL

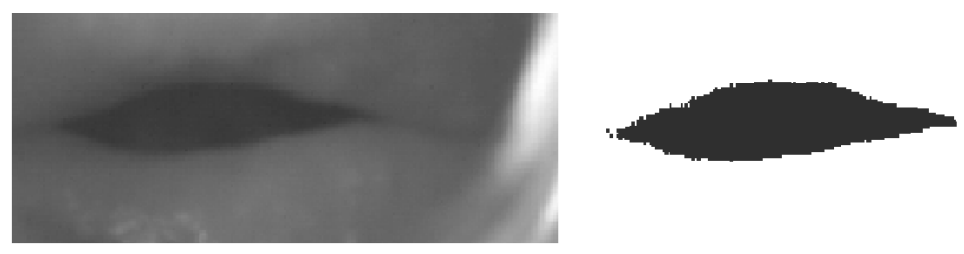

FIG. 2. A sample lip image, including an example of the isolated open area. 
Stevenson, JASA-EL
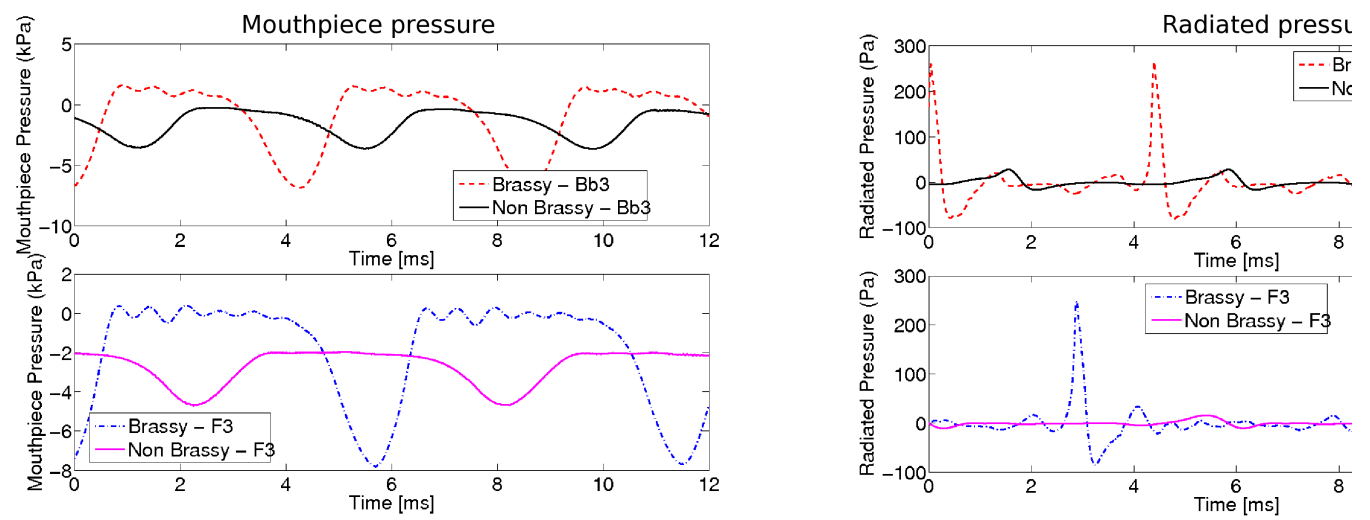

FIG. 3. Mouthpiece (left) and radiated (right) waveforms for brassy and non-brassy playing. Notes $\mathrm{Bb}_{3}$ (upper) and $\mathrm{F}_{3}$ (lower) on the tenor trombone. (Colour online) 
Stevenson, JASA-EL
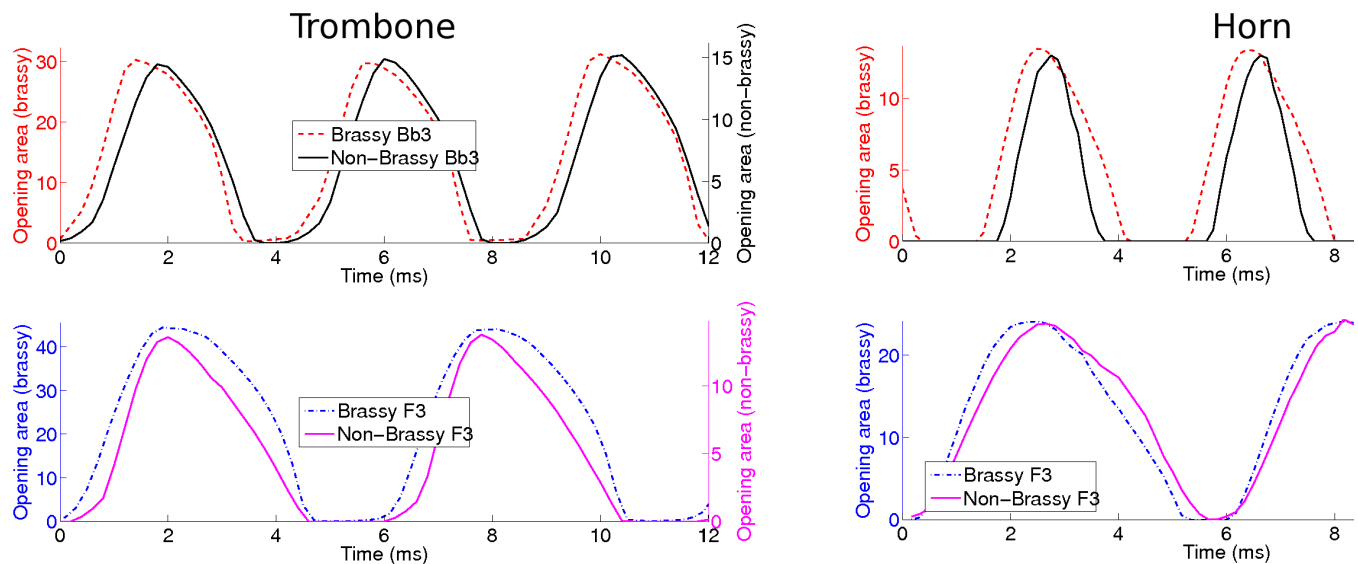

FIG. 4. Lip open areas for brassy and non-brassy playing for two notes on the trombone (left) and two on the horn (right). All areas are given in $\mathrm{mm}^{2}$. The data pairs share a common time-axis but each data set has its own y-axis, effectively normalising the data for ease of comparison. (Colour online) 
Stevenson, JASA-EL

\begin{tabular}{|c|c|c|c|c||c|c|c|}
\cline { 3 - 8 } \multicolumn{2}{c|}{} & \multicolumn{3}{c||}{ Mouthpiece pressure } & \multicolumn{3}{c|}{ Radiated pressure } \\
\hline Instrument & Note & $S C(n b)(H z)$ & $S C(b)(H z)$ & $\frac{S C(b)}{S C(n b)}$ & $S C(n b)(H z)$ & $S C(b)(H z)$ & $\frac{S C(b)}{S C(n b)}$ \\
\hline \multirow{2}{*}{ Trombone } & $\mathrm{B}_{3}$ & 304 & 369 & 1.2 & 716 & 1816 & 2.5 \\
& $\mathrm{~F}_{3}$ & 251 & 392 & 1.6 & 562 & 2462 & 4.4 \\
\hline \multirow{2}{*}{ Horn } & $\mathrm{C}_{4}$ & 425 & 504 & 1.2 & 559 & 1258 & 2.2 \\
& $\mathrm{~F}_{3}$ & 422 & 623 & 1.5 & 655 & 1150 & 1.8 \\
\hline
\end{tabular}

TABLE I. Spectral centroids (SC) for both non-brassy (nb) and brassy (b) notes, calculated for both the mouthpiece pressure and the radiated sound. 


\section{List of Figures}

FIG. 1 An overview of the complete experimental setup (left) for the horn showing the placement of the microphones, camera, and lightsource. The transparent mouthpieces (right) for both trombone and horn. (Colour online) . . . . . . 9

FIG. 2 A sample lip image, including an example of the isolated open area. . . . . . 10

FIG. 3 Mouthpiece (left) and radiated (right) waveforms for brassy and non-brassy playing. Notes $\mathrm{Bb}_{3}$ (upper) and $\mathrm{F}_{3}$ (lower) on the tenor trombone. (Colour online) . . . . . . . . . . . . . . . . . . . .

FIG. 4 Lip open areas for brassy and non-brassy playing for two notes on the trombone (left) and two on the horn (right). All areas are given in $\mathrm{mm}^{2}$. The data pairs share a common time-axis but each data set has its own y-axis, effectively normalising the data for ease of comparison. (Colour online) . . . 

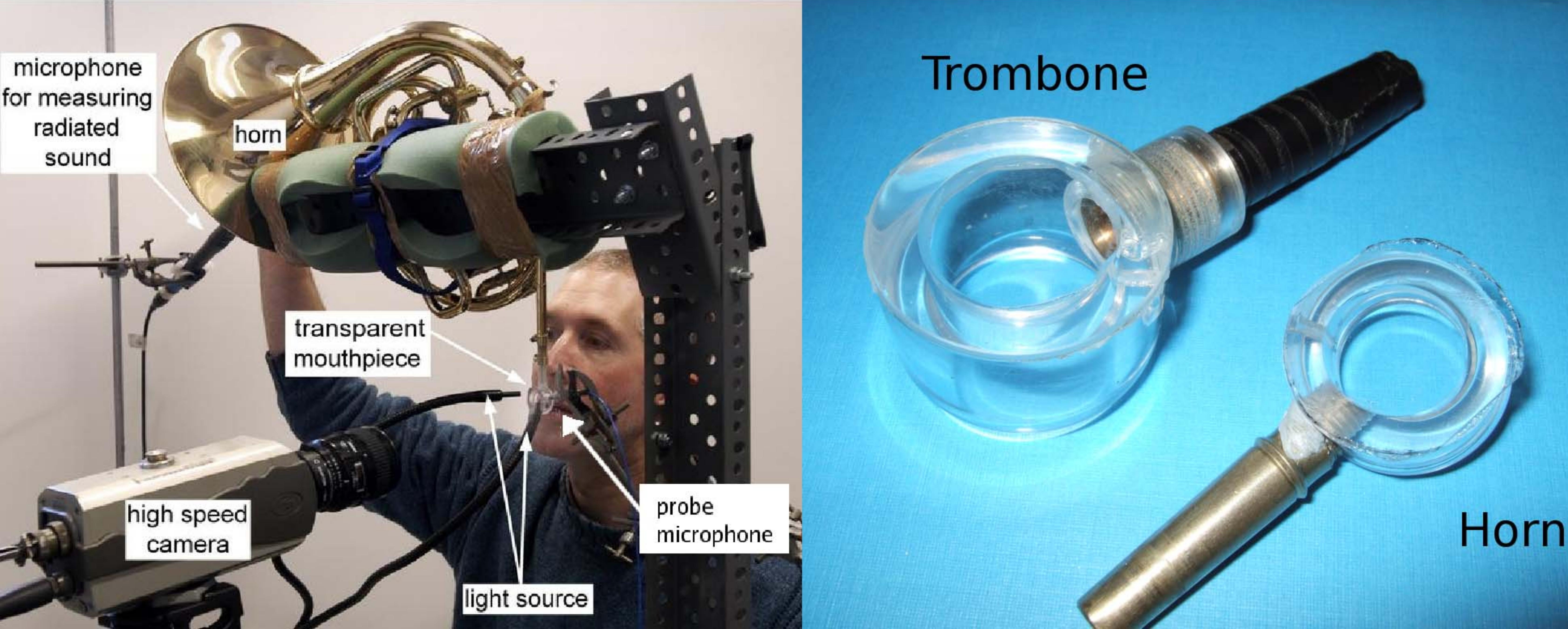

Trombone
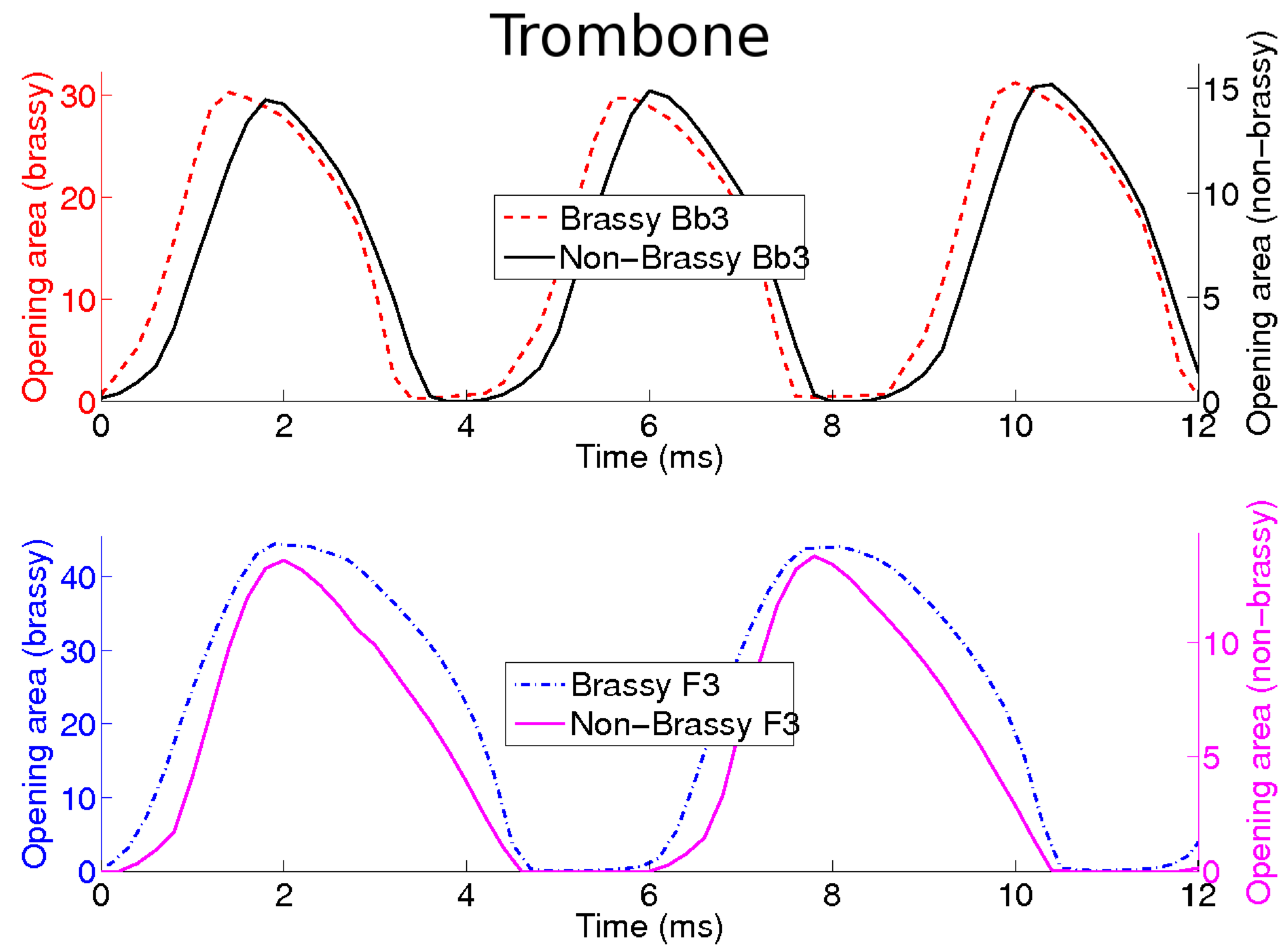
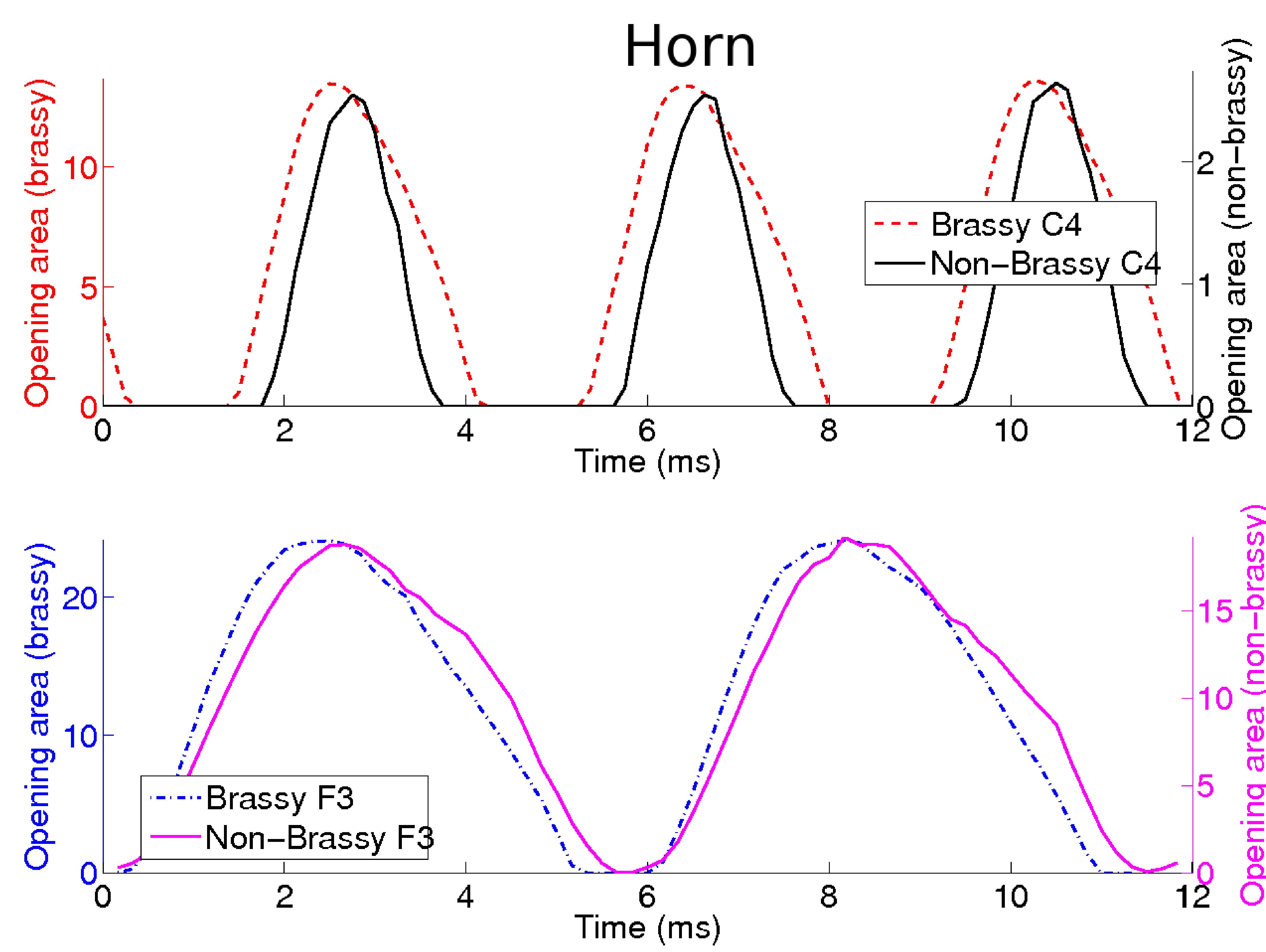